\title{
The interaction of 1,4-diketones with thiazyl chloride $(\mathrm{N} \equiv \mathrm{SCl})$
}

\author{
Sean M. Laaman ${ }^{a}$, Otto Meth-Cohn ${ }^{a}$, and Charles W. Rees ${ }^{a, b}$ \\ ${ }^{a}$ Chemistry Department, University of Sunderland, Sunderland, SR1 3SD, UK \\ ${ }^{b}$ Mailing address: Chemistry Department, Imperial College of Science, Technology and \\ Medicine, London, SW7 2AY \\ E-mail: otto.meth-cohn@sunderland.ac.uk
}

Dedicated to our dear and long-time friend, Douglas Lloyd, on his $80^{\text {th }}$ birthday

\begin{abstract}
Thiazyl chloride $(\mathrm{N} \equiv \mathrm{SCl})$ thermally derived from the preformed trimer and that made from the interaction of urethane, thionyl chloride and pyridine in benzene (Katz reagent) react somewhat differently with dibenzoyl -ethane, -ethene ( $\mathrm{E}$ and $\mathrm{Z}$ ) and -ethyne. In all cases, 3,4-dibenzoyl1,2,5-thiadiazole is formed but with Katz reagent a by-product is also formed, 5-benzoyl-3phenylisothiazole from the ethane and ethyne and 1-ethoxycarbonylamino-1,2-dibenzoylethene from the ethenes. With Katz reagent tetraphenylcyclopentadienone gives 3,4,5,6-tetraphenyl-2pyridone and its $O$-ethoxycarbonyl derivative.
\end{abstract}

Keywords: Thiazyl chloride, 1,4-diketones, urethane, thionyl chloride, isothiazole, Katz reagent

\section{Introduction}

Katz and co-workers ${ }^{1}$ showed that a mixture of ethyl carbamate, thionyl chloride and pyridine in a suitable boiling solvent generates thiazyl chloride $[\mathrm{N} \equiv \mathrm{SCl}]$, a much more effective and convenient source of this useful reagent than the traditional methods. We have demonstrated elsewhere $^{2}$ that this mixture which we refer to as the 'Katz reagent', efficiently converts suitable furans into isothiazoles. The close parallel between the action of this mixture and of thiazyl chloride [which is in equilibrium with its trimer $\mathbf{1}$ in solution] generated from its trimer is not always observed however, particularly when the substrate can react with thionyl chloride or ethyl carbamate, as the following results show.

1,2-Dibenzoyl -ethane, -ethene (E and $\mathrm{Z}$ ) and -ethyne all react with the preformed trimer $\mathbf{1}$ in refluxing tetrachloromethane to give only 3,4-dibenzoyl-1,2,5-thiadiazole 2 in modest yield (40-44\%) probably by way of cycloaddition or cyclisation mechanisms. ${ }^{3,4}$ These substrates react differently with Katz reagent under 'standard' conditions [ethyl carbamate (4.5 mmol), thionyl chloride $(4.5 \mathrm{mmol})$ and pyridine $(1.5-2.0 \mathrm{mmol})$ in benzene $(20-25 \mathrm{~mL})$ stirred at room 
temperature for $30 \mathrm{~min}$ followed by addition of the substrate $(1 \mathrm{mmol})$ and heating under reflux until the substrate was consumed (48, 36 and $4 \mathrm{~h}$ respectively].

1,2-Dibenzoylethane gave the same major product as with the trimer, 3,4-dibenzoyl-1,2,5thiadiazole 2 , in similar yield (45\%) together with 5-benzoyl-3-phenylisothiazole 3 (13\%). Isothiazole $\mathbf{3}$ is the known product from 2,5-diphenylfuran, and thionyl chloride was shown to convert 1,2-dibenzoylethane into 2,5-diphenylfuran in refluxing benzene.

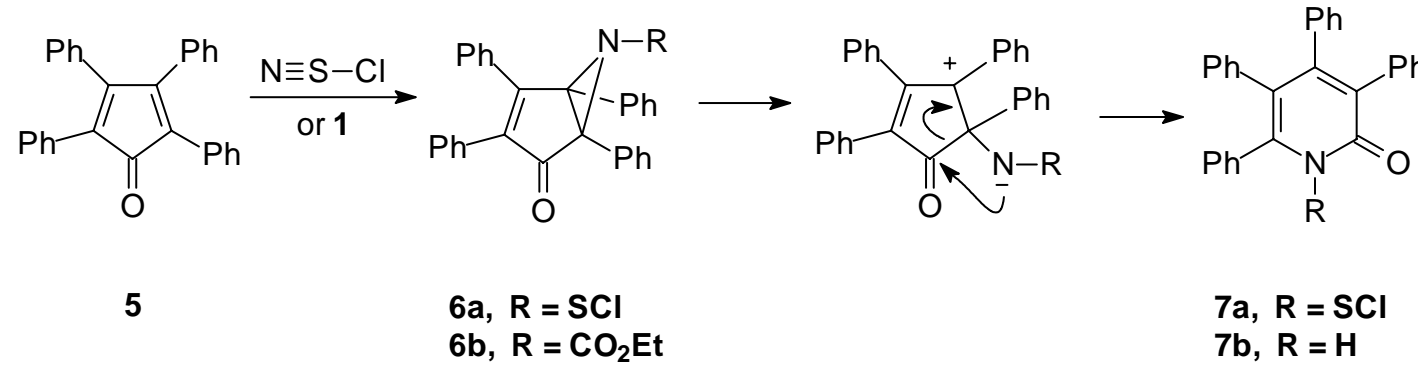

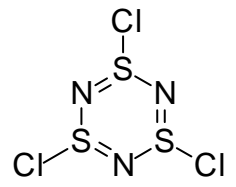

1<smiles>CCOC(=O)c1nc(-c2ccccc2)c(-c2ccccc2)c(-c2ccccc2)c1-c1ccccc1</smiles>

8

\section{Scheme 1}

A different diversionary reaction was observed with E- and Z-1,2-dibenzoylethene; both gave a small amount of 3,4-dibenzoyl-1,2,5-thiadiazole 2 (7 and 18\% respectively) together with a new major product, 1-ethoxycarbonylamino-1,2-dibenzoylethene 4 (42 and 34\% respectively). The indicated trans configuration of the two benzoyl groups in urethane $\mathbf{4}$ is indicated by the low-field hydrogen-bonded NH signal in its ${ }^{1} \mathrm{H}$ NMR spectrum. A blank experiment showed that this urethane $\mathbf{4}$ was not converted into the thiadiazole $\mathbf{2}$ which is probably derived from the alkene and trimer $\mathbf{1}^{3}$ The urethane 4 could result from a Michael-type addition of ethyl carbamate to the electron-deficient alkene, and the alkane so formed could be oxidised, possibly via $\mathrm{N}$-chlorination. Indeed, heating E-1,2-dibenzoylethene with equimolar urethane in benzene and pyridine for 36 hours gave 1-ethoxycarbonylamino-1,2-dibenzoylethane in 74\% yield. Katz has shown that this mixture can behave as an oxidising and chlorinating medium, though he did not observe the formation of analogues of $\mathbf{4}$ in his naphthoquinone conversions.

1,2-Dibenzoylethyne gave the expected thiadiazole 2 (27\%) together with a substantial amount of isothiazole 3 (31\%). In the dibenzoylethane reaction we assumed that this isothiazole was formed from 2,5-diphenylfuran, but it is hard to see how this compound could be formed from dibenzoylethyne. Isothiazole $\mathbf{3}$ was not isolated from treatment of the ethyne with trimer $\mathbf{1}$, and its mode of formation here is as yet unknown. 
The reactions of dibenzoylethenes can be compared with that of another Michael acceptor, tetraphenylcyclopentadienone (tetracyclone) 5. With trimer 1 this gave 3,4,5,6-tetraphenyl-2pyridone $7 \mathbf{b}(56 \%)$ after crystallisation from ethanol. ${ }^{5}$ With Katz reagent it gave the same product (37\%) together with its $O$-ethoxycarbonyl derivative $8(26 \%) ; 8$ was shown to give $7 \mathbf{b}$ under the reaction conditions. A possible pathway for the trimer reaction could be dissociation to the monomer, $\mathrm{N \eta SCl}$, and addition of this to a carbon-carbon double bond of the cyclopentadienone ring to give the fused aziridine $\mathbf{6 a}$;

Table 1. Reaction of 1,4-diketones with $\mathrm{NH}_{2} \mathrm{CO}_{2} \mathrm{Et}, \mathrm{SOCl}_{2}$ and pyridine in boiling benzene

Diketone<smiles>O=C(CCC(=O)c1ccccc1)c1ccccc1</smiles><smiles>O=C(/C=C\C(=O)c1ccccc1)c1ccccc1</smiles><smiles>O=C(/C=C/C(=O)c1ccccc1)c1ccccc1</smiles><smiles>O=C(C#CC(=O)c1ccccc1)c1ccccc1</smiles>

\section{Products $(\%$ yield $)$}

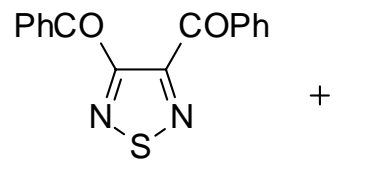

$2(45)$

$2(18)+$<smiles>CCCOc1cc(-c2ccccc2)ns1</smiles>

$3(13)$<smiles>CCOC(=O)/C(=C\C(=O)c1ccccc1)C(=O)c1ccccc1</smiles>

$4(42)$

$4(34)$

The addition could be nucleophilic in character via $\mathrm{N}=\mathrm{S}^{+}-\mathrm{Cl}$, or nitrenoidal and concerted, via: N-S-Cl. The aziridine could rearrange as shown to give the $N$-chlorosulfanylpyridone $7 \mathbf{a}$ which would hydrolyse to $\mathbf{7 b}$ on work-up. With the Katz reagent there could be a similar pathway of nucleophilic addition of ethyl carbamate followed by an oxidation step, possibly via $\mathrm{N}$-chlorination, as proposed for the dibenzoylethenes above, to give the ethoxycarbonylaziridine 6b which could rearrange as before to give the pyridones isolated.

Thus we see that differences are to be expected in the reactions of trimer $\mathbf{1}$ and Katz reagent where the substrate reacts irreversibly with thionyl chloride, for example by cyclodehydration, or with ethyl carbamate, for example by Michael-type addition. 
In conclusion, Katz reagent could well behave differently to trimer-derived thiazyl chloride, particularly with potential Michael acceptors and with substrates that are oxidised or chlorinated by thionyl chloride.

\section{Experimental Section}

General Procedures. The general conditions were as described earlier. ${ }^{2}$ Dibenzoylethane, Edibenzoylethene and tetraphenylcyclopentadienone were purchased from Lancaster Synthesis or from Aldrich. Dibenzoylethyne was made from dibenzoylethene according to the literature. ${ }^{6} \mathrm{Z}$ Dibenzoylethene was made from 2,5-diphenylfuran with lead tetraacetate according to the literature. $^{7}$

\section{General reaction conditions for use of Katz reagent}

A solution of ethyl carbamate $(402 \mathrm{mg}, 4.51 \mathrm{mmol})$, thionyl chloride $(536 \mathrm{mg}, 4.51 \mathrm{mmol})$ and dry pyridine $(2.0 \mathrm{~mL})$ in dry benzene $(22 \mathrm{~mL})$ was stirred for $30 \mathrm{~min}$ at room temperature, after which the substrate was added $(1.05 \mathrm{mmol})$. The mixture was then heated under reflux until the starting material had disappeared. The solvent was removed under vacuum and the brown residue was dissolved in dichloromethane $(10 \mathrm{~mL})$. This solution was washed with aqueous hdrochloric acid $(2 \mathrm{M}, 3 \times 10 \mathrm{~mL})$, then water, dried $\left(\mathrm{MgSO}_{4}\right)$ and evaporated to leave a brown residue which was purified by flash chromatography to give the following products:

From 1,2-dibenzoylethane. $48 \mathrm{~h}$ reflux. Using 5\% ethyl acetate/hexane as eluant the known 5benzoyl-3-phenylisothiazole 3 was obtained as a colourless oil (36 mg, 13\%) identical with a literature prepared ${ }^{5}$ sample by IR and ${ }^{1} \mathrm{H}$ NMR spectroscopy and the known 3,4-dibenzoyl-1,2,5thiadiazole 2, (126 mg, 45\%)as colourless needles, mp 126-127 ${ }^{0} \mathrm{C}$ (lit. ${ }^{3} \mathrm{mp} 128-129{ }^{0} \mathrm{C}$ ).

1,2-Dibenzoylethane (250 mg, $1.04 \mathrm{mmol}$ ) and thionyl chloride (149 $\mathrm{mg}, 1.26 \mathrm{mmol}$ ) in benzene $(20 \mathrm{~mL})$ were heated under reflux for $36 \mathrm{~h}$ and the solvent removed, the residue dissolved in dichloromethane and washed with water. The organic layer was dried $\left(\mathrm{MgSO}_{4}\right)$ and the solvent removed, the residue being purified by flash chromatography (hexane) to give 2,5-diphenylfuran (47 mg, 20\%) as colourless crystals, $\mathrm{mp} 83-84{ }^{\circ} \mathrm{C}$, identical with authentic material.

From $\boldsymbol{E}$-1,2-dibenzoylethene. $36 \mathrm{~h}$ reflux. Using 5\% ethyl acetate in hexane as eluant were obtained the known ${ }^{2}$ 3,4-dibenzoyl-1,2,5-thiadiazole $2(2 \mathrm{mg}, 7 \%)$ and 1-ethoxycarbonylamino1,2-dibenzoylethene 4 (146 mg, 42\%), as a colourless solid, mp 100-102 ${ }^{0} \mathrm{C}$. Found: (m/z, EI) 323.1146. Calc. for $\mathrm{C}_{19} \mathrm{H}_{17} \mathrm{NO}_{4}, 323.1158$. $v_{\max }(\mathrm{KBr}) 3232(\mathrm{NH}), 3070,2989,2962,2857,1735$ (CO), 1681 (CO), 1627, 1589, 1469, 1380, 1353, 1280, 1180, 1072, 1006, 968, 883, 736, 690, $582 \mathrm{~cm}^{-1} ; \delta_{\mathrm{H}}\left(\mathrm{CDCl}_{3}\right) 1.35\left(3 \mathrm{H}, \mathrm{t}, J=7.3, \mathrm{CH}_{3}\right), 4.34\left(2 \mathrm{H}, \mathrm{q}, J=7.3, \mathrm{CH}_{2}\right), 6.61\left(1 \mathrm{H}, \mathrm{s}, \mathrm{H}_{2}\right)$, 7.42-7.75 (6H, m, Ar H's) 7.82-8.20 (4H, m, Ar H's), $11.50(1 \mathrm{H}, \mathrm{s}, \mathrm{NH}) ; \delta_{\mathrm{C}}\left(\mathrm{CDCl}_{3}\right)$ 14.1, 62.9, $99.9,128,0,128.7,128.8,129.1,133.1,133.8,135.2,137.9,152.2,152.6,190.1,191.9 . \mathrm{m} / \mathrm{z}$ (CI) $324\left(\mathrm{M}^{+}+1,100 \%\right), 323\left(\mathrm{M}^{+}\right), 278,218,146,105$. 
From Z-1,2-dibenzoylethene. $36 \mathrm{~h}$ reflux. Using 5\% ethyl acetate in hexane as eluant gave 3,4dibenzoyl-1,2,5-thiadiazole 2 (57 mg, 18\%) and 1-ethoxycarbonylamino-1,2-dibenzoylethene 4 (116 mg, 34\%), mp 100-102 ${ }^{0} \mathrm{C}$.

From dibenzoylethyne. $4 \mathrm{~h}$ reflux. Using 5\% ethyl acetate in hexane as eluant gave 5-benzoyl3-phenylisothiazole 3 (76 mg, 31\%) and 3,4-dibenzoyl-1,2,5-thiadiazole 2 (86 mg, 27\%).

From tetraphenylcyclopentadienone (tetracyclone) (5). $12 \mathrm{~h}$ reflux. Using $30 \%$ ethyl acetate in hexane as eluant gave 2-ethoxycarbonyloxy-3,4,5,6-tetraphenylpyridine $\mathbf{8}(80 \mathrm{mg}, 26 \%)$ as a pale yellow oil; Found: (m/z, EI) 471.1835. Calc. For $\mathrm{C}_{32} \mathrm{H}_{25} \mathrm{NO}_{3}, 471.1834$. $v_{\max }$ (neat) 3054, 2923, 2854, 1762 (CO), 1600, 1592, 1531, 1442, 1403, 1369, 1253, 1214, 1095, 1052, 979, 883, 759, $701,617,532 \mathrm{~cm}^{-1} ; \delta_{\mathrm{H}}\left(\mathrm{CDCl}_{3}\right) 1.17\left(3 \mathrm{H}, \mathrm{t}, J=7.25, \mathrm{CH}_{3}\right), 4.13\left(2 \mathrm{H}, \mathrm{q}, J=7.25, \mathrm{CH}_{2}\right), 6.74-$ 6.77 (2H, m, Ar H's), ), 6.84-7.02 (8H, m, Ar H's) 7.10-7.20 (8H, m, Ar H's), ), 7.30-7.34 (2H, $\mathrm{m}, \mathrm{Ar} \mathrm{H}$ 's $) \delta_{\mathrm{C}}\left(\mathrm{CDCl}_{3}\right) 14.0,64.8,126.6,126.7,127.15,127.2,127.5,127.55,127.6,127.7$, $130.05,130.2,130.3,130.3,130.35,131.3,134.2,134.6,137.1,137.6,152.75,153.4,155.8 . \mathrm{m} / \mathrm{z}$ (CI) $472\left(\mathrm{M}^{+}+1,100 \%\right), 471\left(\mathrm{M}^{+}\right), 428(25), 400$ (18). Also isolated was 3,4,5,6-tetraphenyl-2pyridone $7 \mathbf{b}$ (95 mg, 37\%), mp 269-270 ${ }^{0} \mathrm{C}$ (lit. ${ }^{5} \mathrm{mp} 271-273{ }^{0} \mathrm{C}$ ).

2-Ethoxycarbonyloxy-3,4,5,6-tetraphenylpyridine (8). To a solution of 3,4,5,6-tetraphenyl-2pyridone $7 \mathbf{b},(25 \mathrm{mg}, 0.06 \mathrm{mmol})$ in dichloromethane $(2 \mathrm{~mL})$ was added sodium bicarbonate $(5$ $\mathrm{mg}, 0.06 \mathrm{mmol})$. To the stirred solution was added ethyl chloroformate $(8 \mathrm{mg}, 0.07 \mathrm{mmol})$ and the stirring continued overnight. Water $(2 \mathrm{~mL})$ was added and the aqueous layer re-extracted with dichloromethane $(2 \times 2 \mathrm{~mL})$ and the combined organic layers dried $\left(\mathrm{MgSO}_{4}\right)$ and evaporated to give pale yellow 2-ethoxycarbonyloxy-3,4,5,6-tetraphenylpyridine 8 (29 mg, $98 \%$ ), spectroscopically identical to the above sample.

Reaction of $\boldsymbol{E}$-1,2-dibenzoylethene with urethane. A solution of ethyl carbamate (42 $\mathrm{mg}$, $0.46 \mathrm{mmol})$, E-1,2-dibenzoylethene $(100 \mathrm{mg}, 0.42 \mathrm{mmol})$ and dry pyridine $(0.5 \mathrm{~mL})$ in benzene $(10 \mathrm{~mL})$ was heated at reflux for $36 \mathrm{~h}$, after which dichloromethane was added and the mixture washed with aqueous hydrochloric acid $(2 \times 10 \mathrm{~mL})$, and then water. The organic layer was dried $\left(\mathrm{MgSO}_{4}\right)$ and evaporated to give 1-ethoxycarbonylamino-1,2-dibenzoylethane, (101 mg, 74\%).

\section{References}

1. Shi, S.; Katz, T. J.; Yang, B. V.; Liu, L. J. Org. Chem. 1995, 60, 1285.

2. (a) Laaman, S. M.; Meth-Cohn, O.; Rees, C. W. Synthesis 1999, 757; (b) Guillard, J. Lamazzi, C.; Meth-Cohn, O.; Rees, C. W.; White, A. J. P.; Williams, D. J. J. Chem. Soc., Perkin Trans. 1 2001, 3297.

3. Duan, X.-G.; Duan, X.-L.; Rees, C. W.; Yue, T.-Y. J. Chem. Soc., Perkin Trans. 1 1997, 2597.

4. Duan, X.-G.; Duan, X.-L.; Rees, C. W. J. Chem. Soc., Perkin Trans. 1 1997, 2831.

5. Duan, X.-L.; Perrins, R.; Rees, C. W. J. Chem. Soc., Perkin Trans. 1 1997; 1617.

6. Zhang, J.-J.; Schuster, G. B. J. Am.. Chem. Soc. 1989, 111, 7149.

7. Dien C.-K.; Lutz, R. E. J. Org. Chem. 1957, 22, 1355. 